\title{
UNA APROXIMACIÓN A LAS NOCIONES DE ANGUSTIA Y DESESPERACIÓN EN SÖREN KIERKEGAARD Y SU PAPEL EN LAS RELACIONES CONCRETAS CON EL PRÓJIMO DE JEAN-PAUL SARTRE
}

\author{
MARÍA FERNANDA GUEVARA RIERA \\ Universidad Católica Andrés Bello
}

\begin{abstract}
RESUMEN: En el siguiente artículo analizaremos las nociones de angustia y desesperación desarrolladas por Sören Kierkegaard en El concepto de angustia y en el Tratado de la desesperación con el fin de resaltar la importancia de las mismas para el autor danés y, a su vez, vislumbraremos su papel determinante en las relaciones concretas con el prójimo descritas por Jean-Paul Sartre en El ser y la nada. Nuestra hipótesis de trabajo establece que Sartre sigue el cuadro de la desesperación kierkergaardiana y que por ello condena al fracaso las relaciones con el prójimo. Nosotros consideramos que las nociones de angustia y desesperación de Kierkegaard analizadas en este artículo constituyen el meollo del problema en el autor francés, pues, sólo a partir del estudio de ellas, se podrá discutir e intervenir el concepto de mala fe en Sartre que determina el fracaso de las relaciones concretas con el prójimo en El ser y la nada.
\end{abstract}

PALABRAS CLAVES: angustia; desesperación; existencialismo; prójimo; Kierkegaard; Sartre.

\section{An approach to the notions of anxiety and despair in Sören Kierkegaard and his role in the concrete relations with the other of Jean Paul Sartre}

ABSTRACT: In the following article we will analyze the notions of anxiety and despair developed by Sören Kierkegaard in The Concept of Anxiety and in the Treaty of Despair in order to highlight their importance for this Danish author and, in turn, we will glimpse his determinant role in the concrete relations with the others described by Jean-Paul Sartre in the Being and the Nothingness. Our working hypothesis states that Sartre follows the Kierkergaardian structure for despair and therefore he condemns to failure the relations with the others. We consider that notions of anxiety and despair of Kierkegaard analyzed in this article are the core of the problem for the French author, because, only by studying them, it will be possible to discuss and intervene the concept of bad faith in Sartre that determines the failure of concrete relationships with the others in Being and Nothingness.

KEY WORDS: despair; existentialism; anxiety; others; Sartre; Kierkegaard.

Nuestra hipótesis de trabajo sostiene que Sartre sigue el cuadro de la desesperación kierkergaardiana en su descripción fenomenológica de las relaciones concretas con el prójimo y que, por ello, condena al fracaso todas las relaciones con el otro, en la medida en la cual, éstas no pueden deslastrarse de la mala fe o inautenticidad que las circunscribe. Así, sostenemos que si superamos la desesperación kierkegaardiana - superación que entrevemos y consideramos posible gracias al análisis que desarrollamos lo largo de este artículo_ podremos rescatar del abismo a las relaciones concretas con el prójimo en Sartre y no suponerlas más como un proyecto fallido de libertades en relación, tal como apuntamos en un trabajo precedente (cf. Guevara, 1998). 
Vale la pena apuntar que, si bien Kierkegaard en El concepto de angustia y en el Tratado de la desesperación mantiene diversos enfoques en torno a la angustia y los caminos que esta habrá de seguir hacia la divinidad, nosotros procedemos a exponer tales nociones centrándonos, exclusivamente, en la angustia mundana por ser de fundamental relevancia para nuestra comprensión de Sartre y de todas las corrientes existencialistas posteriores a Kierkegaard. Todo el planteamiento teológico queda intencionalmente excluido de nuestro enfoque, si bien será atendido cuando así lo requiera la exégesis.

\section{LA NOCIÓN DE ANGUSTIA}

Para Kierkegaard la angustia es el estado anímico fundamental que experimenta todo hombre con respecto al mundo y, a su vez, en relación a sí mismo. De esta manera, la angustia hacia el mundo es angustia ante la nada como infinitud de posibilidades y la angustia ante sí mismo es desesperación de lograr la plenitud de su propio ser. Vale entonces decir que la angustia y la desesperación no son nociones radicalmente diferentes.

Para comenzar, digamos que, según Kierkegaard, el hombre es captado a partir de una división de carácter ontológico. Puesto que, para poder comprendernos y explicarnos existencialmente, es necesario admitir la existencia de un adentro que corresponde a la interioridad del sujeto, y un afuera que, de la misma manera, se refiere al mundo y al cuerpo que se encuentra arrojado en él. Antropológicamente, el existente es entendido por Kierkegaard como una «síntesis irreductible entre alma y cuerpo. Síntesis que encarna el espíritu». (Kierkegaard, 1979: 61-67). La interioridad del hombre se caracteriza por la intranquilidad, por la angustia, por la inquietud de no saber la suerte de su ser, y a su vez, por no poder encontrar la paz espiritual: «La inquietud es el verdadero comportamiento con respecto a la vida, con respecto a nuestra realidad personal». (Kierkegaard, s.f.: 12).

Según Kierkegaard, la angustia es resultado de la falta de significado con el cual el mundo se presenta al hombre, insertado en la propia infinitud de posibilidades existenciales. El hombre se angustia, vive en constante aflicción experimentando su ser atiborrado de posibilidades, sin definición certera de su ser-hombre, sin norma alguna establecida que guíe su actuar. De forma tal que experimentar la angustia es enfrentar el desmoronamiento de las verdades consideradas como absolutas. Por lo tanto, escoger es arriesgar el propio ser en cada elección, viviendo la angustia de la elección de sí mismo:

«El espíritu tiene angustia de sí mismo, no puede librarse de sí mismo; tampoco puede comprenderse a sí mismo, mientras se tiene a sí mismo fuera de sí mismo... de la angustia no puede huir, porque la ama; amarla no puede propiamente, puesto que la huye». (Kierkegaard, 1979: 62).

El existente, arrojado en el mundo, se enfrenta a la lucha continua por definirse. La exterioridad en la que se instala genera inquietudes y conflictos en la propia interioridad del hombre. Así, éste experimenta angustia porque no sabe con certeza si su libertad está siendo ejercida plena y correctamente en las decisiones que toma. Como decíamos anteriormente, el mundo ofrece una infinitud tal de posibilidades 
y de resistencias que el sujeto debe negar o realizar. Pero, aún más angustiante es la incertidumbre de no saber si lo elegido es lo más adecuado para uno mismo.

La angustia es originaria al nacimiento del ser, es una condición del hombre de la que este no puede librarse: lo configura ontológicamente. El vértigo de la libertad es abismal porque no se puede escapar de él aunque así se pretenda. Sobre esa infinitud de posibilidades, el hombre debe escoger desde su propia subjetividad, es decir, desde sí mismo, desde aquello que él considere como correcto. El hombre en Kierkegaard se encuentra replegado en su intimidad, presionado por el peso de su existencia. El peso de la existencia es tal porque en soledad el individuo debe construir la «verdad subjetiva», es decir, su verdad dirigida hacia lo absoluto. Para Kierkegaard, esto supone un largo debate interior, donde la agonía de la angustia permite los saltos cualitativos de la existencia. Estos saltos vienen a ser los tres estadios de la existencia: estético, ético y religioso; cada cual corresponde a niveles superiores de la vida del individuo en relación con la divinidad. Para poder dar dichos saltos existenciales se requiere de la angustia vivida reflexivamente.

Ahora bien, siguiendo el hilo conductor del autor danés debemos preguntarnos cómo se genera la angustia en el hombre.

\subsection{Génesis de la angustia}

Según Kierkegaard, el nacimiento del hombre se pierde en los albores de la creación divina. La angustia no posee un nacimiento temporal, dado que sus lineamientos son ontológicos; pero ¿cómo se da cuenta el hombre de la configuración de la misma? En el estado de inocencia del hombre podemos ver al espíritu en reposo, este ignora la nada:

«En este estado hay paz y reposo; pero hay al mismo tiempo otra cosa, que, sin embargo, no es guerra ni agitación, pues no hay nada con qué guerrear ¿Qué es ello? Nada». (Kierkegaard, 1979: 59)

No existe en el mundo ni en el hombre una determinación de su proyecto de vida. La nada irrumpe desde el nacimiento de la especie humana, puesto que no poseemos un conocimiento total de nuestro estar en el mundo y, menos aún, cómo debe ser ese estar en el mundo ${ }^{1}$. En este supuesto estado de inocencia, la nada desarticula al existente:

«Nada. Engendra angustia. Este es el profundo misterio de la inocencia: que es al mismo tiempo angustia. Soñando proyecta el espíritu de antemano su propia realidad; pero esta realidad es nada; y la inocencia ve continuamente delante de sí esta nada». (Kierkegaard, 1979: 59).

\footnotetext{
1 Podemos acotar que la angustia ante la nada en Kierkegaard corresponde a cierto «darse cuenta» de la indeterminación de la existencia particular en el mundo, aun cuando posteriormente la presencia divina garantice el salto cualitativo y el reposo total del espíritu. La angustia mundana implica la vivencia en el estadio ético (superado el estadio estético del goce de los sentidos o placeres), con los múltiples dilemas de la elección para alcanzar el estadio religioso. De ahí, la importancia del recogimiento interior para Kierkegaard puesto que permite la existencia auténtica, donde el individuo reflexivamente aprende a vivir con la paradoja de su existir: éste es siempre finito pero siempre abierto a la posibilidad y por ello, debe elegir.
} 
El espíritu no reconoce la lucha contra algo determinado; en el ensueño inocente, el espíritu se angustia ante la nada: «Toda inocencia, no obstante su seguridad y su paz ilusoria, es angustia, y nunca la inocencia tiene tanto miedo como cuando su angustia carece de objeto (...)». (Kierkegaard, s.f.: 37). Así, la angustia en Kierkegaard no es un producto de la imaginación: ella es real, ontológica. El existente se angustia frente a la libertad plena de posibilidades que aguarda por una investidura de significado: «(...) la angustia es la realidad de la libertad como posibilidad antes de la posibilidad» (Kierkegaard, 1979: 60). Esto acontece porque la elección no está dada de por sí. El espíritu escoge sin el piso seguro de alguna verdad objetiva.

Ahora bien, como ya hemos tenido oportunidad de decir, según Kierkegaard, el hombre es: «una síntesis psíquica y corporal que se encuentra unida por el espíritu». (Kierkegaard, 1979: 61). Sin embargo, el espíritu no es un conciliador total de esta síntesis, pues en él conviven diferencias y disparidades. Por ello, el espíritu se angustia de sí mismo y, además, se angustia por no poder deshacerse de esa síntesis contradictoria que es y que lo posibilita: «En la angustia se denuncia el estado del cual se anhela salir y se denuncia por medio de la angustia, porque el anhelo no basta para salvarse». (Kierkegaard, 1979: 77). De ahí que el espíritu, en dicha síntesis, no es sino el choque de sus múltiples diferencias: la paradoja de la existencia como tensión irreconciliable entre finito-infinito.

Se comprende así mejor cómo la angustia existencial kierkergaardiana es ese sentimiento de lo posible que se le presenta al hombre. La infinitud de posibilidades presentadas por la existencia; infinitud cercada, a su vez, por la elección finita que genera nuevas posibilidades: «(...) en la angustia reside la infinitud egoísta de la posibilidad, que no tienta como una elección, pero angustia, pesando con su dulce opresión». (Kierkegaard, 1979: 81).

\subsection{El existente}

El interior espiritual del existente mostrado por Kierkegaard es una síntesis no realizada que se ejerce hacia afuera, en un ir y venir de decisiones, en un ir y venir de caminos. Es decir, que el interior del existente se debate ininterrumpidamente con las asperezas de ese mundo que lo acoge y lo rechaza sin cesar. El existente lucha tanto en su interior como en los actos proyectados. La angustia no promueve el quietismo. Como vimos, ella es sufrimiento: el existente sufre en la desazón de la nada, en la infinitud de caminos que el mundo le muestra y, a su vez, en la necesidad de vivir la opción de la finitud a través de las decisiones.

Es de vital importancia entender que el hombre kierkergaardiano se encuentra anclado en un mundo finito, aun cuando experimenta las infinitas posibilidades que le otorga el mismo. Esto hace que experimente a la vez la infinitud en la existencia, pero también la imposibilidad de convertirse en infinito: «El hombre era, pues, una síntesis de alma y cuerpo; pero al par es una síntesis de lo temporal y de lo eterno». (Kierkegaard, 1979: 107). El ansia de infinitud y, a su vez, el peso de la finitud angustian al hombre y lo hacen porque él mismo es la angustia existencial que anhela lo absoluto.

Así, sin el amparo ni la custodia de un fundamento más allá de la propia existencia particular que garantice el uso de la libertad, el hombre sufre, pero no por 
ello, deja de actuar ${ }^{2}$. Ciertamente la acción permite aminorar el sentimiento de la angustia y del hombre como existente auténtico ${ }^{3}$. Pero, es importante destacar que Dios como absoluto en Kierkegaard no limita, no interfiere, no supervisa la acción del existente... he ahí su aflicción. De ahí que, sea hora de preguntarnos por la presencia de Dios en la angustia del hombre.

\subsection{Entre infinitos}

Tengamos presente que Kierkegaard discrimina dos infinitos: como indeterminación (la nada como infinidad de posibilidades) y como totalidad (la idea de Dios). Esto traerá importantes consecuencias para la cuestión del sujeto y las relaciones concretas con el otro expuestas por Sartre.

Ya hemos visto cómo nuestra existencia está determinada ontológicamente según Kierkegaard: somos un espíritu en síntesis estremecida que debe experimentarse continuamente desde el arrojo. No somos por definición quietud, sino más bien, un sujeto que se vive contradictoriamente. Desde esta síntesis, el hombre experimenta la infinitud, mientras, a su vez, ésta lo conforma espiritualmente determinando su situación con el mundo y consigo mismo.

Así, pues, entendida la infinitud como indeterminación de posibilidades que el mundo nos otorga, la noción de la nada se abre paso. Pero, no es que el hombre sea indeterminación radical y de una manera desdeñosa se aniquile como ser. Más bien, la radicalidad consiste en que el existente no puede escapar de la libertad que posee para erigirse, no puede huir ni resguardarse en algún dogma o verdad reconocida.

Dado lo anterior, podemos subrayar que la infinitud como indeterminación afecta al ser que, a partir de la multiplicidad de posibilidades mundanas, debe escoger desde una interioridad en debate. Sin embargo, dicha indeterminación no infesta al ser para aniquilarlo en una absoluta indeterminación, es decir, no lo convierte en nada. La indeterminación en Kierkegaard es la infinitud de posibilidades que posee

2 El universo existencialista cristiano desarrollado por Kierkegaard supone la existencia de un absoluto más allá del hombre mismo. Ahora, mientras el existente se encuentre arrojado en el mundo, estará desprotegido puesto que sólo él puede escoger su camino. Dios como absoluto no garantiza el «buen» uso de la libertad. Precisamente, la angustia viene dada por esa intuición originaria del sujeto y, su principal esfuerzo será descubrir cómo y qué debe escoger en esta existencia para alcanzar, posteriormente, la divinidad. La angustia dirigida por la fe permite la existencia auténtica y alcanzar el estadio religioso: «Si al comienzo de su educación entiende mal la angustia, de tal forma que ésta no le conduce a la fe, sino que le aparta de ella, está perdido». (KIERKEGAARD, 1979: 181).

3 «(...) cuanto más hondamente se angustia tanto más grande es el hombre». (KIERKEGAARD, 1979: 181). Sirva la nota para señalar que la «calidad» de vida del existente, es decir su grandeza, está «determinada» por la asunción radical de la angustia o no. Sólo la vivencia de la misma en recogimiento casi absoluto, permite los saltos cualitativos de la existencia: de la inauténtica a la auténtica. Es decir, pasar del estadio estético (goce simple y particular de la existencia) al ético (preocupación por suprimir las particularidades y dirigirlas hacia lo divino) y, a su vez, finalmente, con la asunción de la fe, alcanzar el estadio religioso. La vida es asumida por Kierkegaard como una tensión irreconciliable; pero no por ello, el existente obvia su camino existencial para sumirse en el quietismo. 
el hombre que exige la toma de decisión finita y, por consiguiente, la vivencia de la angustia.

Ahora bien, por otro lado, el infinito es pensado también como totalidad. Esta totalidad se conoce ontológicamente como la idea o presencia de Dios y, por lo tanto, en el seno del existencialismo cristiano juega un papel primordial. Como hemos acotado, Dios no interfiere en las acciones del hombre; este último es igualmente absoluto en su mundo y sobre él reposa la construcción de su ser. Alcanzar a Dios desde la experiencia existencial del desprotegimiento es el propósito de Kierkegaard. Así, la presencia de Dios garantiza el reposo de la existencia, si — condicionalmente- el sujeto ha experimentado y superado la angustia radical.

Pero, entonces, ¿cómo se reconoce al otro en Kierkegaard si el hombre desfallece continuamente en su interior? La infinitud como indeterminación niega al existente que se deshace a cada instante. El hombre está inmerso en su proyecto vital y pretender una seguridad absoluta es una ilusión que bien pronto se disuelve ante las múltiples posibilidades que se le presentan al existente. Así, el espíritu se encuentra en una ardua dialéctica existencial, donde la síntesis o recuperación total no es posible. Por ello, la lucha por el proyecto subjetivo se convierte en lo más importante y urgente. Desde este enfoque, ¿cómo llegar al otro? ¿Es acaso el otro relevante en Kierkegaard? ${ }^{4}$

\subsection{El instante, la angustia y la elección ${ }^{5}$}

La noción del instante está inseparablemente unida a la noción de angustia que hemos venido exponiendo. El existente auténtico, inmerso en un mundo donde decide constantemente, enfrenta el tiempo de manera inusual para aquellos que no están comprometidos con la reflexión existenciaria:

«El tiempo es, pues, la sucesión infinita; la vida, que es en el tiempo y pertenece sólo al tiempo, no tiene ningún presente. Cierto que a veces suele definirse la vida sensible diciendo que es en el momento y sólo en el momento». (Kierkegaard, 1979: 108).

4 El «proyecto subjetivo» corresponde al estadio ético de la existencia como hemos mencionado anteriormente. Esto supone un sujeto solitario comprometido con la reflexión existenciaria para otorgar significados a su existencia, siempre en relación con la divinidad. Así, el sujeto «espera» alcanzar el estadio religioso. Pareciera que sólo allí, la presencia del otro en Kierkegaard podría tener sentido. Vale el comentario para citar lo resaltado por Collins, James en su libro El pensamiento de Kierkegaard en relación a lo sugerido: «Sólo la fe puede vencer la soledad en principio y dar ánimo a nuestros intentos humanos de entrar en comunión unos con otros. El efecto catastrófico de la categoría del individuo es el hacer evidente la futileza de todos los esfuerzos sociales emprendidos sin tener una fe común en Dios y sin reconocimiento humilde de nuestra verdadera condición». (KIERKEGAARD, s.f.: 126)

5 La edición utilizada de El concepto de angustia traduce "momento», mientras que Aranguren J. L., en el prólogo de la misma y diversos intérpretes de Kierkegaard consultados utilizan en el apartado de la temporalidad el término «instante». Nosotros haremos la cita textual, respetando el vocablo «momento». A su vez, en nuestros comentarios utilizaremos el término «instante». 
Este instante de Kierkegaard condensa la eternidad, la posibilidad y, a su vez, la elección finita que determina los posibles subsiguientes. La vida sensible, la existencia mundana no conoce otro tiempo, salvo el instante: el hombre elige a cada momento. Esa elección angustia al existente, puesto que, de esas elecciones depende el sentido de su vida. Es decir, que en un instante elegimos comprometiéndonos en nuestra elección, corriendo el riesgo de la misma.

El párrafo anterior nos muestra cómo el instante es el único tiempo posible para el hombre según Kierkegaard, y además, cómo contribuye a configurar la experiencia de la angustia originaria. A fin de cuentas, en un instante el hombre experimenta lo abismal, lo desfondado de su ser, y además, lo infinitamente angustiante de escoger el camino de su existencia que determinará su acercamiento o no al absoluto. Comprendido este fenómeno, podemos ahora decir que el otro en Kierkegaard no es el hombre, sino Dios mismo, en tanto que toda la vida está dirigida hacia lo totalmente Otro y la angustia de la elección reside precisamente en ello.

Se entiende así cómo el hombre en Kierkegaard, a cada instante, determina su destino eterno a través de sus opciones. Constantemente, el hombre compromete la posibilidad de alcanzar a Dios, lo verdaderamente infinito por él anhelado. Es decir que el hombre se juega la eternidad en una lucha contra la nada, experimentando su finitud. El mundo se presenta absurdo para el existente puesto que nada posee sentido en sí mismo, salvo el que éste le otorgue en cada elección.

\subsection{Dimensión moral de la angustia}

Para Kierkegaard la angustia existencial tiene, además, una dimensión moral. Esto significa que el hombre «debe» reconocer, entre sus posibles, la elección que sea más consecuente con la dirección de su existencia, a saber, la de alcanzar el estadio religioso: y, sin embargo, como lo comenta Maceiras:

«El hombre está siempre al borde de un abismo sin la certeza de qué es lo bueno y qué es lo malo, complicando las decisiones de la libertad. Queda así existencialmente vinculado con la angustia». (Maceiras, 1985: 135).

Esto último podría parecer una contradicción, pues si Kierkegaard ha insistido una y otra vez sobre la libertad radical que tiene el hombre de encontrar el bien y el mal, ¿cómo puede establecer la superioridad de un estadio de la existencia sobre otro? ¿Cómo puede afirmar que Dios es el reposo absoluto para el hombre? Nosotros nos separamos de esta posición y sólo subrayamos que el hombre debe escoger y vislumbrar en su elección, la bondad y la maldad de la opción a partir de los fines que él haya establecido y del valor que otorgue a la elección misma6.

Según Kierkegaard, la gran lucha del espíritu en el debate de la elección radica en mantenerse abierto a la infinitud, conservando la riqueza de las alternativas,

6 Ahora bien, ese debate interior es la reflexión existencial misma sobre lo que es o deja de ser a cada momento el existente; además, el valor que acarreará ese debate será completamente subjetivo, particular y es así, como se reconoce al espíritu en su inquietud. Inquietud que reflejarán los hombres al momento de relacionarse, de ejercer su libertad y de encontrar barreras por ser diferentes los compromisos o las visiones sobre determinada situación o sentimiento que posean. 
en las propias palabras del autor sería lo siguiente: «El educado por la angustia es educado por la posibilidad, y solo el educado por la posibilidad está educado con arreglo a su infinitud». (Kierkegaard, 1979: 182).

Así, tenemos que el espíritu angustiado en Kierkegaard, cuando decide vivir auténticamente, debe luchar constantemente por conservar la libertad. Hemos dicho que la angustia convive con el hombre aunque éste trate de olvidarla. Y, de la misma manera, el espíritu que desea olvidar la angustia nunca alcanza a eliminarla: sólo permanece más alejado del camino hacia lo absoluto.

\section{La NOCIÓN DE DESESPERACIÓN: DiMENSIONES Y FORMAS}

Pasamos a exponer e interpretar la noción de desesperación en Kierkegaard para, posteriormente, arribar a Sartre y reconocerla en la mala fe que infesta a las relaciones concretas con el prójimo sartreanas y señalar, así, la posibilidad de su superación, rescatando del fracaso a las relaciones concretas con el prójimo descritas por Jean-Paul Sartre en El ser y la nada..

Para Kierkegaard la desesperación equivale a la pretensión de hacer coincidir el propio ser a cada instante: la desesperación tiene sus raíces ontológicas en la búsqueda radical de la totalidad perdida en la caída. La desesperación es la angustia agonizante del hombre que elige al borde del abismo sin certeza de sí. Es la enfermedad mortal experimentada por el hombre. En palabras del propio Kierkegaard: «(...) es una ventaja infinita poder desesperarse y, sin embargo, la desesperación no es sólo la peor de las miserias, sino también nuestra perdición» (Kierkegaard, s.f.: 23).

La enfermedad mortal socava las fuerzas del yo incapaz de lograr por sí sólo reposo y conformidad. Sin embargo, la ventaja de esta enfermedad mortal consiste en que, mediante ella, y el conflicto que la constituye, el hombre puede acercarse más a la comprensión de su ser en comunión con el absoluto divino. El yo enfermo de muerte es incapaz de estar muerto: "Estar enfermo de muerte es no poder morirse». (Kierkegaard, s.f.: 27). A partir de esta paradoja, Kierkegaard analiza la desesperación y la caracteriza como el intento de recuperación de sí por parte del sujeto. En palabras de Kierkegaard:

«(...) es la desesperación la enfermedad mortal, ese suplicio contradictorio, ese mal del yo: morir eternamente, morir sin poder morir, sin embargo, morir la muerte. Pues morir quiere decir que todo ha terminado, pero morir la muerte significa vivir la propia muerte; y vivir un sólo instante es vivirla eternamente». (Kierkegaard, s.f.: 28).

Y, sin embargo, «la superioridad del hombre sobre el animal, está pues en ser pasible de ese mal; la del cristiano sobre el hombre natural, en tener conciencia de la enfermedad, así como su beatitud está en poder ser curado de ella». (Kierkegaard, s.f.: 23). Como se desprende de este pasaje, la desesperación funciona en Kierkegaard como motor para ir avanzando a través de los diversos estadios que caracterizan la existencia y dar o no los saltos cualitativos dentro la misma. Es un motor porque: «(...) a cada instante que estamos sin ella, la hemos rechazado o la rechazamos, pero ella retorna, es decir, que a cada instante que desesperamos, contraemos la desesperación». (Kierkegaard, s.f.: 25). 
Kierkegaard considera que el sujeto, en la asunción del proyecto reflexivo-existencial, puede recuperarse pero nunca como una cosa acabada, sino más bien, como un ser arrojado en el mundo, sin apoyo ontológico alguno, a no ser que, como el cristiano, opte por el salto de la fe. Será la ausencia de esta opción religiosa en el existencialismo ateo de Sartre lo que volverá aún más dramática la posición del para-sí y sus relaciones con el otro a nuestro entender.

\subsection{El yo}

¿Quién sufre la desesperación? El yo, esa síntesis de alma y de cuerpo, representa la unidad humana que genera y padece la desesperación. Kierkegaard nos muestra al yo en un "hoyo» representado por el interior de su ser, en medio del cual, según nuestra interpretación, debe el existente expiarse y reconocerse.

«El hombre es espíritu ¿Pero qué es el espíritu? Es el yo. Pero entonces, ¿qué es el yo?... es en la relación, la orientación interna de esa relación: el yo no es la relación, sino el retorno a sí misma de la relación». (Kierkegaard, s.f.: 19).

Así, el yo para Kierkegaard es de carácter reflexivo y sensitivo, es decir, el yo razona, pero a la vez vive sus razonamientos. Sus reflexiones son siempre de carácter existencial, lo cual quiere decir que el hombre es la perspectiva desde la cual se mide todo aspecto cognoscitivo.

Para caracterizar aún más la desesperación en Kierkegaard y relacionarla concretamente con la mala fe sartreana, hagamos notar que ésta posee tres formas, una encubierta y dos explícitas. La más abrumadora es aquella donde el hombre pretende ignorar en lo más íntimo de su ser la presencia de la desesperación: el individuo que no percibe su desesperación se encuentra más desesperado que nunca porque para Kierkegaard ser hombre implica desesperarse. Es esta una pretensión inauténtica en cuanto aquí el sujeto se rehúye a sí mismo y ésta es precisamente la definición sartreana de la mala fe.

El yo que pretende estar libre de la desesperación es uno que supone ser un individuo resuelto, para el cual la vida ya no presenta problema alguno. Pero tal creencia no pasa de ser un engaño, pues no produce en el existente ninguna efectiva conciliación consigo mismo y con el mundo. Aquí, el sujeto en realidad: «(...) desespera de no poder devorarse ni deshacerse de su yo, ni de aniquilarse. Tal es la fórmula de la acumulación de la desesperación, el crecimiento de la fiebre en esa enfermedad del yo». (Kierkegaard, s.f.: 28).

La asunción auténtica de la angustia ante sí mismo implica, en cambio, la vivencia radical de la desesperación, no rehuirla, más bien, enfrentarla, viviseccionarla para que ésta no nos condene a la enfermedad mortal. No se trata de eliminarla, sino de asumirla de manera tal que contribuya a formar existencialmente al sujeto arrojado en el mundo. En este sentido, para el existencialismo la tranquilidad espiritual es un acto de deshonestidad. Cuando el hombre se decide finalmente a enfrentar la desesperación, ella se presenta en otras dos formas que Kierkegaard resume de la siguiente manera: a) donde el ser no quiere ser él mismo; b) donde desesperadamente desea ser él mismo.

"Quien desespera quiere, en su desesperación, ser él mismo. Pero entonces, ¿no quiere desprenderse de su yo? En apariencia, no; pero observando de más 
cerca, siempre se encuentra la misma contradicción. Ese yo, que ese desesperado quiere ser, es un yo que no es él (...)» (Kierkegaard, s.f.: 30)

La relación de la desesperación kierkergaardiana en Sartre la dejamos para el siguiente apartado que funciona a modo conclusiones finales de este artículo, sin embargo, vamos a puntualizar inmediatamente que en el universo ateo sartreano se ha negado la posibilidad de un ente todopoderoso como el existente en Kierkegaard. De ahí que nosotros consideramos que todas las expectativas que el sujeto kierkegaardiano repone en la divinidad se trasladen al otro hombre en el autor francés, sobrecargando las relaciones concretas con el prójimo. Se perfila así la alternativa radical que Sartre sólo alcanza a presentar en el último capítulo de El ser y la nada: una de dos, o el sujeto autárquicamente se fundamenta a sí mismo o lo hace a partir del otro. Pero en ambos casos, Sartre mostrará el fracaso necesario de este proyecto asomando una tercera opción, a saber, que el sujeto decida ya no recuperarse sino mantenerse a distancia de sí. Al final de su obra, en Perspectivas morales, Sartre indicará, en las primeras dos opciones, un proyecto de mala fe, dejando entrever en el segundo camino un proyecto auténtico todavía por construir.

Retomando nuestro hilo conductor, en Kierkegaard el hombre desesperado, que no alcanza la plenitud de su existencia, intenta asirse a una parte de su ser, transformándose en "algo» acabado o, en su defecto, en un mero despilfarro de posibilidades. En otras palabras, el sujeto pretenderá asirse en lo finito o divagar en el infinito. El existente intenta deshacerse de su yo en la desesperación de lo finito-infinito. Precisamente esta lectura es la que retoma Sartre en El ser y la nada cuando afirma que el para-sí (añadimos nosotros de mala fe) o pretende ser mera facticidad o mera trascendencia intentando evadir la tensión existencial que constituye la existencia y, por ello, condena al fracaso todas las relaciones concretas con el prójimo.

Ahora bien, ¿hay cabida en la caracterización realizada por Kierkegaard para la felicidad? Acaso, ¿puede existir placer y dicha en un yo donde se conjugan a cada instante con temor y temblor lo finito y lo infinito? Para Kierkegaard anhelar la felicidad es una nueva sombra que oculta en lo más íntimo del ser, la angustia ante la nada y ante sí mismo:

«¿Pero la felicidad es una categoría del espíritu? Absolutamente no. Y en su fondo, hasta en su basamento más secreto, también la habita la angustia, que es desesperación y que sólo quiere ocultarse allí, no teniendo la desesperación un lugar predilecto más apetecible que el último fondo de la felicidad». (Kierkegaard, s.f: 37$)$.

Según esto, la felicidad y su búsqueda persistente apartan al hombre de sí mismo y lo extravían irremediablemente. Al intentar obviar la tensión existencial, la felicidad sumerge al existente en la más terrible de las desesperaciones: aquella que no se conoce a sí misma. La felicidad, al igual que la tranquilidad del espíritu, es el recurso del individuo inauténtico que no enfrenta la existencia. Por supuesto que ello no significa que el hombre kierkegaardiano no experimente la dicha; lo hace cada vez que mantiene enrumbado su proyecto, es decir, cada vez que supera un estadio de la existencia. Sin embargo, la dicha sólo se alcanza plenamente, de manera última y definitiva, a través del salto de la fe. 


\subsection{Desesperación y libertad}

Kierkegaard reconoce que el hombre vive en cada instante lo posible y lo necesario: son éstos los elementos contradictorios que conforman su libertad.

«El yo está formado de finito e infinito. Pero su síntesis es una relación que, aunque derivada, se refiere a sí misma, lo que es la libertad. El yo es libertad. Pero la libertad es la dialéctica de dos categorías, de lo posible y de lo necesario». (Kierkegaard, s.f.: 40).

Finalmente, y para concretar esta entrega, corresponden a este conflicto las dos formas explícitas de la desesperación que indicáramos hace poco y que, según nuestra lectura, Sartre retoma en las relaciones concretas con el prójimo descritas en El ser y la nada condenándolas al fracaso. Encontramos primero la desesperación de la infinitud, donde el yo se desdibuja y se pierde en la imaginación para no volver sobre sí mismo:

«(..) El hombre, de sentimiento absorbido por lo imaginario, viértase cada vez más en el infinito, pero sin devenir cada vez más el mismo, puesto que no deja de alejarse de su yo». (Kierkegaard, s.f.: 45).

Y en la segunda forma la misma suerte acontece donde el hombre pretende reducir su experiencia vital a sistemas formales:

«Tal es la desesperación de la finitud. Un hombre puede realizar perfectamente en ella una vida temporal, y en el fondo, tanto mejor, una vida humana en apariencia, conquistando el elogio de los demás, el honor, la estima y la prosecución de todos los fines terrenos». (Kierkegaard, s.f.: 56).

Pero, por otro lado, en la misma cotidianidad presenciamos otro tipo de desesperación: por temor a la elección entre varias posibilidades, el hombre prefiere anclarse en la trivialidad fatalista de la costumbre, para que ésta le indique qué camino debe escoger, alcanzando, supuestamente, la paz y el sosiego de su yo. El sujeto quiere escapar de la angustia volcándose al determinismo de la funcionalidad: «El determinista, el fatalista son desesperados que han perdido su yo, puesto que para ellos no existe más que la necesidad»(Kierkegaard, s.f.: 54). Necesidad de seguridad que ha anulado al yo y lo ha arrojado a un universo acabado, total y cerrado.

La necesidad que aparece en la cotidianidad es de signo contrario a la acción potente y plena de necesidad de un sujeto que elige desde su libertad. Esta última es aquella capaz de afirmar un camino, y negar a la vez otros posibles, reconociendo la angustia y desesperación que se derivan de ese único acto en donde la afirmación es toda uno con la negación:

«El desesperado consciente no sólo debe saber exactamente qué es la desesperación, sino que ha de tener conocimiento pleno de sí mismo, ya que la lucidez y la desesperación no se excluyen». (Kierkegaard, s.f.: 62).

Hemos finalizado nuestra lectura crítica de las nociones de angustia y desesperación en Kierkegaard y en el siguiente apartado conclusivo conversaremos con Sartre delimitando las consecuencias de la noción de angustia y desesperación en las relaciones concretas con el prójimo descritas en El ser y la nada. 
3. A modo de CONClusiones. Angustia y deSESPERACión: La MALA fe SARTREANA Y LAS RELACIONES CONCRETAS CON EL PRÓJIMO.

Ha resultado que la angustia es el sentimiento originario del hombre ante la existencia misma, ante la multiplicidad que ésta le otorga, mientras que la desesperación es la angustia ante sí mismo: angustia experimentada por el hombre que intenta escapar de este sentimiento originario y fundamental de sí. Para Kierkegaard, la angustia se presenta primariamente a nivel individual.

A lo largo de nuestra exposición, la angustia fue entendida como el motor de la existencia humana, desde la cual los sujetos emprenden su quehacer en el mundo. A partir de allí podemos establecer que las relaciones intersubjetivas dentro del existencialismo - en sus diversas versiones inspiradas en Kierkegaard- están enmarcadas en proyectos que asumen o descartan la angustia existencial como constitutiva de la verdad subjetiva: la aproximación a la existencia desde un proyecto auténtico o un proyecto inauténtico dependerá de la asunción o no de la angustia existencial.

En Sartre la angustia es la toma de conciencia de la libertad humana ante un mundo absurdo: "La angustia es el modo de ser de la libertad como conciencia de ser y en la angustia está en su ser cuestionándose a sí misma». (Sartre, 1993: 34). Por su parte, la desesperación, según Sartre, surge del fracaso del intento de superar la angustia a través de las relaciones concretas con el prójimo. Así, en el último párrafo dedicado a las actitudes hacia el prójimo en El ser y la nada, Sartre indica que ninguna de ellas permite salir del círculo. Ni siquiera la actitud del odio, última tentativa para salirse del círculo vicioso de las relaciones con el otro, logra suprimir la angustia:

«El odio no permite salir del círculo. Representa, simplemente la última tentativa, la tentativa de la desesperación. Después del fracaso de esta tentativa, no queda al para-sí sino regresar al círculo y dejarse pelotear indefinidamente entre ambas actitudes fundamentales, de la una a la otra». (Sartre, 1993: 511).

Pero, una vez instalado en el ir y venir, la desesperación está presente al final de cada figura concreta. Sin embargo, en una nota a pie de página, Sartre acota lo siguiente:

«Estas consideraciones no excluyen la posibilidad de una moral de liberación y salvación. Pero ésta, debe alcanzarse al término de una conversión radical, que no podemos tratar aquí». (Sartre, 1993: 511)

Es precisamente la posibilidad de esta conversión radical — que se efectúa gracias al psicoanálisis existencial- lo que nos permite afirmar que las relaciones concretas con el prójimo descritas en El ser y la nada son una descripción de las actitudes de mala fe que siguen el cuadro kierkergaardiano de la desesperación. Lo sorprendente es que el propio Sartre no lo haya explicitado. En efecto, el psicoanálisis existencial pretende modificar el valor a partir del cual los sujetos encaran su existencia. Sartre advierte que el sujeto asume los valores a partir de la existencia vivida como una falta radical de $u n$ significado fundamental de la existencia y busca irremediablemente ser causa sui, reparase, completarse. De esta manera, Sartre no discute la carencia del sujeto, dada su descripción fenomenológica, sino más bien, la aproximación que poseen los sujetos a la misma. Los individuos se conducen en 
la cotidianidad, de manera tal, que buscan socavar plenamente su vacío existencial. Esta búsqueda absoluta es de mala fe y reproduce el cuadro de la desesperación kierkergaardiana.

Puntualizando, nosotros hemos considerado que las dos formas de desesperación kierkergaardianas — de ser o sólo finitud o sólo infinitud- vuelven a presentarse concretamente en las dos actitudes fundamentales ante el prójimo descritas por Sartre en El ser y la nada. Así, en Sartre el afán de querer ser uno mismo equivaldría al deseo de aniquilar al otro para ser mera libertad, mera trascendencia, la cual correspondería a la forma de la desesperación de la infinitud kierkergaardiana; mientras que el no querer ser uno mismo en la relación con el otro e intentar hacerse aniquilar por él para cosificarse, volver cosa o macizo inerte correspondería a la desesperación de la finitud en Kierkegaard.

La angustia y la desesperación de Kierkegaard analizadas en este artículo constituyen para nosotros el meollo del problema en el autor francés, pues, sólo a partir del estudio de ellas, se podrá discutir e intervenir el concepto de mala fe que determina el fracaso de las relaciones concretas con el prójimo en El ser y la nada. Y, también, sólo desde ellas, cobra sentido la afirmación de que lo que Sartre presenta en el capítulo dedicado a las relaciones concretas con el prójimo es una descripción de actitudes de mala fe. De todas formas, sólo si se reinterpreta el texto sartreano desde la perspectiva que hemos introducido a lo largo de nuestro análisis podemos evitar que la antropología de El ser y la nada cobre el sesgo negativo con la cual muchos comentaristas la han tipificado. Llevándole la contraria al propio Sartre, se desprende que hay espacio en su obra para afirmar que el hombre no es una pasión inútil.

El hombre en Sartre no es una síntesis contradictoria de alma y cuerpo como en Kierkegaard. El punto de partida del análisis sartreano es la conciencia de raigambre cartesiana. De esta manera, la ontología parte del estudio del ser, «(...) y la conciencia no es un modo particular de conocimiento, llamado sentido interno o conocimiento de sí: es la dimensión de ser transfenoménica del sujeto (Sartre, 1993: 18)». Así, la única manera de conocer al ser es en tanto aparece y es el cogito la manifestación del mismo. En el universo sartreano no hay interior ni exterior, sino que: «Las apariciones que manifiestan al existente no son ni interiores ni exteriores: son equivalentes entre sí, y remiten todas a otras apariciones, sin que ninguna de ellas sea privilegiada» (Sartre, 1993: 11). De forma tal que el sujeto en Sartre se encuentra arrojado en el mundo, pleno de posibilidades para realizarse a partir de las elecciones que le hacen frente. Ahora bien, el hombre vuelto hacia sí se vive en la contradicción, no por ser una síntesis estremecida como en Kierkegaard, sino por ser una conciencia vacía, arrojada en el mundo.

De esta manera, la presencia de un sujeto que se interroga sobre sí y sobre su entorno acontece desde una unidad irreductible que constituye su ser con el mundo. El existente se interroga en la nada que lo constituye, es decir, desde el vacío radical que implica la carencia de fundamentos gnoseológicos y ontológicos que determinan el sentido y razón fundamental de la existencia. Entonces, habrá de preguntarse ¿qué soy?, ¿quién soy? La respuesta es «nada». «El existente es conciencia, ipseidad, pura intencionalidad de aprehender contenidos: la conciencia está vacía de contenidos»y, por tanto, el hombre vuelto hacia sí es nada: un para-sí que no encuentra donde asirse. 
«La conciencia no tiene nada de sustancial, es una pura apariencia, en el sentido de que no existe sino en la medida en que aparece. Pero precisamente por ser pura apariencia, por ser un vacío total (ya que el mundo entero está fuera de ella), precisamente por esa identidad en ella de la apariencia y la existencia, puede ser considerada como lo absoluto». (Sartre, 1993: 24)

Así pues, se distingue la nada como factibilidad del ser, es decir, como la no determinación de la conciencia y, entonces, la plena libertad de la misma para construirse, de la nada como acción negativa que el existente ejerce sobre sí, convirtiéndose de esta manera en su terrible padecimiento. Dado lo anterior, vemos cómo la nada en la conceptualización sartreana pasa a ser de negación determinada a negación absoluta del ser como la desesperación kierkergaardiana:

«El Ser por el cual la Nada adviene al mundo es un ser para el cual, en su Ser, es cuestión de la Nada de su Ser: el ser por el cual la Nada adviene al mundo debe ser su propia Nada». (Sartre, 1993: 64).

En efecto, Sartre nos expone que el ser en su condición de nihilizador constante, se encuentra infestado de no-ser; entendido este no-ser como la negación constante de sí, donde el negar determinado ${ }^{7}$ establece la diferenciación de ser esto o aquello. Por lo pronto, la nada como negación determinada adviene al mundo por el ser que se interroga a sí mismo y, de esta manera negativa, se relaciona con el mismo:

«La interrogación es, pues, por definición, un proceso humano. El hombre se presenta, por ende, al menos en este caso, como un ser que hace surgir y desplegarse la Nada en el mundo, en tanto que, con ese fin, se afecta a sí mismo de no-ser». (Sartre, 1993: 62).

De forma tal que la nada es analizada por Sartre como carencia y, dándose en el núcleo del para-sí, éste buscará eliminarla constantemente. Así, la mala fe se presenta — dentro de esa intencionalidad primitiva - como tentativa de restituir la completud del ser, es decir, para ser cosa acabada o en-sí, causa sui. De esta manera, la nada como negación determinada pasa a ser el motor absoluto del movimiento de trascendencia del para-sí.

Este universo es distinto al kierkegaardiano puesto que la angustia de un ser pleno de posibilidades y complicaciones se experimenta a partir de notables diferencias ontológicas y antropológicas. Estas diferencias aportarán otras características en el existente que pretende relacionarse con el otro. Más aún, en Sartre el sujeto descubre no tener escapatoria alguna salvo requerir de la presencia del otro para erigir la noción de su ser a diferencia de Kierkegaard que se encuentra encerrado en su subjetividad y los saltos de la existencia se dan hacia lo absoluto en absoluta soledad. En Sartre la angustia es de un para-sí que no puede recuperarse en la intimidad de su ser puesto que reconoce que la facticidad de su cuerpo en el mundo se lo impide y, entonces, puede elegir en recuperarse o huir de sí, en otras palabras, en ser auténtico o inauténtico dependiendo de la asunción de la angustia descrita anteriormente a la luz de Kierkegaard.

Resulta de nuestro recorrido de la noción de angustia y desesperación en Kierkegaard y de nuestra conversación con Sartre que si se asume auténticamente la

7 Negar determinado significa que niego ser una silla o un animal invertebrado. 
angustia como motor de la existencia ésta da paso a relaciones fructíferas con el prójimo. La encrucijada por la cual han de transitar los sujetos en Sartre sería: asumir la angustia como desesperación y emprender el proyecto de recuperación total de sí o, en cambio, transformarla en motor de la existencia auténtica, en la que el hombre se mantiene siempre a distancia de sí. Esto último permitiría una subjetividad que ya no se asume desde la carencia, sino, más bien, desde la «plenitud» lograda sobre la incompletud del ser. (Guevara, 2000: 112). Sólo así, la existencia del sujeto no estaría definida como un proyecto fallido y nosotros consideramos que solo con la comprensión de la angustia y desesperación en Kierkegaard se puede «salvar» al Sartre pesimista que condena a todas las relaciones concretas con el otro, en la medida en la cual, la desesperación kierkergaardiana no resulte la única aproximación posible a las relaciones concretas con el prójimo y se abra, entonces, la posibilidad de un segundo encuentro más allá del descrito por Sartre en El ser y la nada.

\section{BiBLIOGRAFÍA}

Aranguren, J. L. (1979). Introduccion. En S. Kierkegaard, El concepto de la angustia (pág. 189). Madrid: Espasa-Calpe.

Barthes, R. (1965). Fragmentos de un discurso amoroso. Mexico: Ediciones Siglo XXI.

Barthes, R. (s.f.). Fragmentos de un discurso amoroso.

Descombes, V. (1982). Lo mismo y lo otro. Madrid.

Desiato, M. (1995). Linamientos de Filosofia. Caracas: UCAB.

Grene, M. (1961). El sentimiento tragico de la existencia. Madrid: Aguilar.

Guevara Riera, F. (2000). Limites de la filosofia moral de Sartre. Caracas: UCAB.

Guevara Riera, M. (1998). Logoi I. Obtenido de El amor en las relaciones concretas con el prójimo. Ontología y ética en El ser y la nada: en http://revistasenlinea.saber.ucab.edu.ve/ temas/index.php/logoi/article/view/459/457

Kierkegaard, S. (1979). El concepto de la angustia. Madrid: Espasa-Calpe.

Kierkegaard, S. (s.f). Tratado de la desesperacion. Santigo Rueda.

Kojeve, A. (1965). Introduccion a la lectura de Hegel. Madrid: 675.

Maceiras, M. (1985). Shopenhauer y Kierkegaard: Sentimiento y pasión. Madrid: Cincel.

Monuier, E. (s.f.). Introduccion a los existencialismos.

Sartre, J.-P. (1993). El ser y la nada. Buenos aires: Losada.

Universidad Católica Andrés Bello

María Fernanda Guevara Riera

Centro de Investigación de la Comunicación

mguevarariera@gmail.com

[Artículo aprobado para publicación en enero de 2018] 
